\title{
LA CIUDAD DE LAS TÉCNICAS MODERNAS
}

\author{
THE CITY OF MODERN \\ TECHNIQUES
}

\author{
ELEONORA MENÉNDEZ \\ (FADU-UBA-Argentina) \\ Facultad de Arquitectura, Diseño y \\ Urbanismo: \\ Universidad de Buenos Aires \\ (FADU-UBA)
}

La arquitectura y el urbanismo denominados modernos intentaron durante décadas modificar el ambiente mediante la aplicación de nuevas formas técnicas. Contando con partidarios como Le Corbusier, las asociaciones poéticas expresadas por el arquitecto en relación con una confianza plena en la era técnica se pueden observar en gran parte de su obra desarrollada durante las primeras décadas del siglo xx. El presente texto analiza las innovaciones tecnológicas presentes en un proyecto urbano de Le Corbusier de la primera posguerra: el Plan Voisin pour Paris, por considerarlo representativo de las relaciones entre técnica y transformaciones culturales en las formas de vida social metropolitana.

técnica, máquina de habitar, formas de vida urbana, bienestar
Recibido: 23 de mayo del 2019

Aprobado: 6 de agosto del 2019

doi: 10.26439/limaq2020.n006.4816

For decades, the so-called modern architecture and urbanism tried to modify the environment by applying new techniques. Le Corbusier was one of its remarkable supporters, and his poetical associations related to the full confidence in the technical era can be found in most part of his work performed during the first decades of the 20th century. This paper analyzes the technological innovations presented in an urban project of the first postwar period by Le Corbusier, Plan Voisin pour Paris, for considering it to be representative of the relation between technique and cultural transformations in the ways of the metropolitan social life.

technique, machine for living, forms of urban 


\section{LA CIUDAD DE LAS TÉCNICAS MODERNAS}

Acaso la enfermedad básica de nuestro tiempo sea una crisis de los deseos y por eso toda la fabulosa potencialidad de nuestra técnica parece como si no nos sirviera de nada. ... y es que el hombre actual no sabe qué ser, le falta imaginación para inventar el argumento de su propia vida.

Ortega y Gasset

En su libro The evolution of Technology, George Basalla (1988) observa que una creencia invocada al momento de explicar descubrimientos técnicos es la idea de invención como resultado de necesidades humanas básicas. Sin embargo, la historia del nacimiento de diversas invenciones modernas revela casos cuyas creaciones no respondieron a requerimientos biológicos, sino que, por el contrario, fueron las innovaciones tecnológicas las que dieron origen a nuevas necesidades. En este sentido, el autor retoma la definición crítica pensada por el filósofo español José Ortega y Gasset que describe la técnica como "la producción de lo superfluo": aquellos inventos realizados por el hombre para modificar su circunstancia o naturaleza y adaptar el medio a sus necesidades, entendiéndolas no como necesidades biológicas (alimentarse, calentarse), sino como aquellas objetivamente superfluas que solo son fundamentales para quienes vivir significa, esencialmente, "vivir bien" o, en otras palabras, que contribuyen a lo que se ha denominado "bienestar".

La arquitectura moderna, llamada a colaborar en la gestión de las ciudades, intentó durante décadas modificar el ambiente cotidiano mediante la aplicación de nuevas formas técnicas con el objetivo de mejorar la calidad de vida. Contando con partidarios notables como Le Corbusier, autor del concepto denominado "máquina de habitar", las asociaciones poéticas expresadas por el arquitecto en relación con una confianza plena en la era técnica se pueden observar en gran parte de su obra desarrollada durante las primeras décadas del siglo xx. Siguiendo la dirección planteada por Basalla, el presente texto se propone analizar las innovaciones tecnológicas presentes en un proyecto urbano de Le Corbusier de la primera posguerra: el Plan Voisin pour Paris, por considerarlo representativo de las relaciones entre técnica y transformaciones culturales en las formas de vida social metropolitana.

\section{ANTECEDENTES: LA CIUDAD DE LABORATORIO}

El progreso económico y social solo puede nacer de problemas técnicos que se solucionen bien.

Le Corbusier, 1925

En 1922, finalizada la Primera Guerra Mundial, el Salón d'Automne, un espacio parisino destinado a la divulgación de obras vanguardistas, organiza 
una exposición sobre "proyectos urbanos", un concepto bastante amplio para la época, e invita al joven Le Corbusier para que participe de la muestra. Antes de comenzar a desarrollar el encargo, el arquitecto solicitó una definición sobre la idea de urbanismo y, en consecuencia, de ciudad, que la exposición buscaba mostrar. El organizador del evento, Marcel Temporal, responde que tiene en mente "el diseño de bancos, kioscos, luminarias, carteles de señalización" sugiriendo: "Mire, ¿por qué no diseña una fuente?". Le Corbusier acepta el encargo: "Bien, diseñaré una fuente, pero detrás de ella ubicaré una ciudad para tres millones de habitantes" (Von Moos, 2002). En efecto, el arquitecto presentó una obra-manifiesto de la idea de urbanismo moderno titulada Ville contemporaine pour trois millions d'habitants en respuesta a las necesidades propias de un contexto de posguerra: producción de viviendas a gran escala, edificios de oficinas y un nuevo esquema para la circulación de vehículos.

La propuesta de "Ciudad contemporánea para tres millones de habitantes" es presentada como un proyecto abstracto, "científico", carente de soporte territorial y posible de ser aplicado en cualquier metrópolis. Tal como su nombre lo señala, se titula "contemporánea" y no "futura" ya que buscaba posicionarse como una propuesta concreta posible de ser realizada técnicamente y no como una utopía futurista.

Procediendo como el técnico en su laboratorio, dejo de lado los casos específicos; aparto todos los accidentes; me preparo un terreno ideal. El objetivo no consistía en vencer situaciones preexistentes, sino llegar con la construcción de un edificio teórico riguroso, a formular principios fundamentales del urbanismo moderno. Dichos principios fundamentales, si son ciertos, pueden constituir el esqueleto de todo sistema de urbanización contemporánea; constituirán la regla según la cual puede hacerse un juego. (Le Corbusier, 2001 p. 48)

El plano general presenta una grilla de ejes perpendiculares y diagonales que organizan lotes de superficies construidas y vegetadas. Los ejes principales ortogonales responden a la orientación norte-sur / este-oeste y en su intersección, en vez de encontrar templos o monumentos, se ubica la "estación", un importante centro de transbordo de pasajeros que incluye cinco niveles subterráneos, un pasaje para peatones situado un nivel por debajo de la primera planta de residencia y una plataforma de aterrizaje elevada para "aviones-taxi". Exceptuando el momento de acceso a los autos estacionados, los peatones apenas tendrían razones para circular por las calles. Estos niveles variados debían acoger diferentes categorías de transportes y servicios, incluida la red de metro existente, hundida a una gran profundidad. Acompañando a los ejes, se ubica la "gran arteria", una pasarela sobreelevada de 40 metros de ancho, para la circulación de vehículos rápidos. Alrededor de este gran espacio público se ubica la "Ciudad de los Negocios" compuesta por altísimos rascacielos cruciformes con fachadas de vidrio (figura 1). 


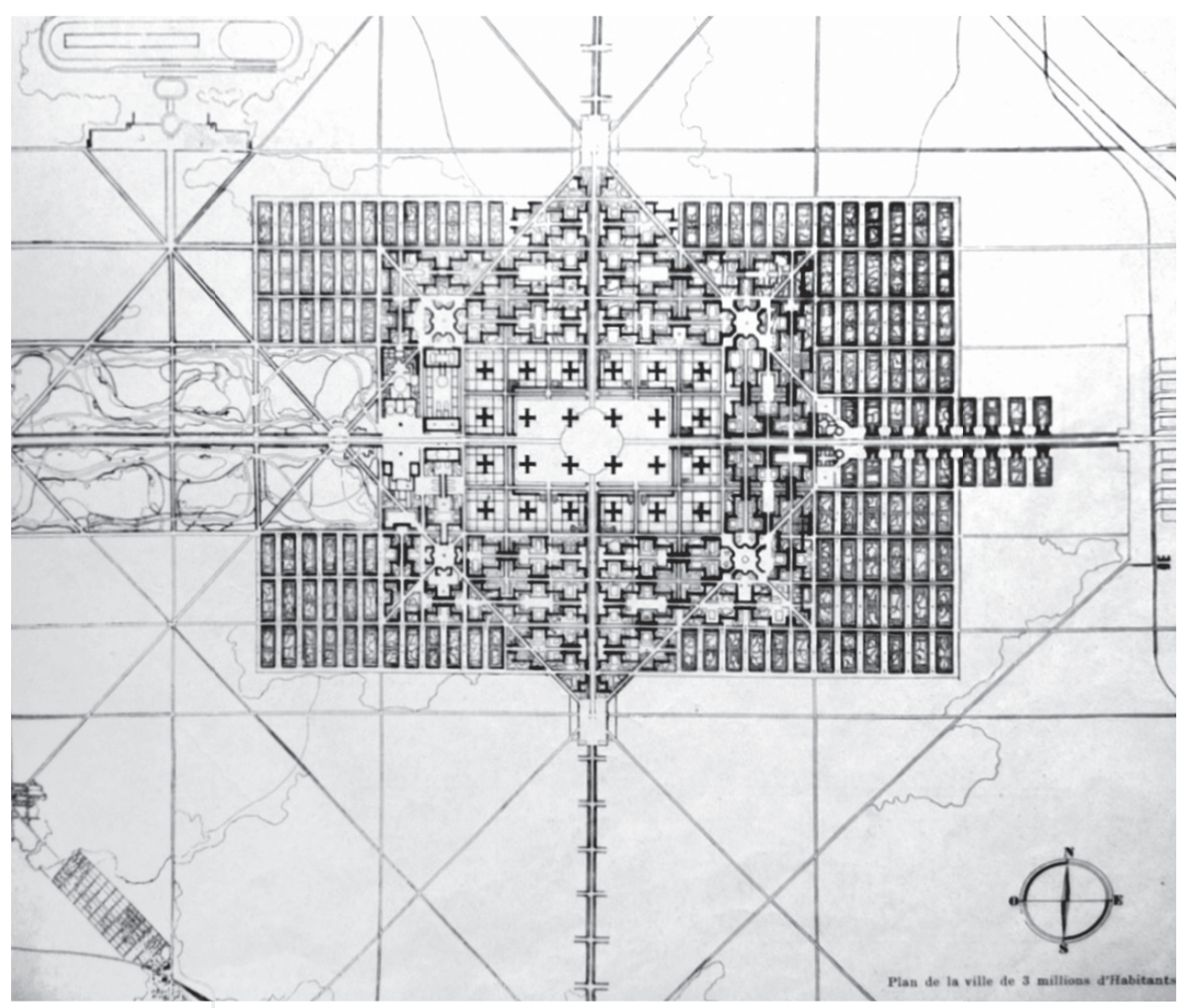

Figura 1

Plan Ville

contemporaine pour trois millions

d'habitants

Fuente:

Le Corbusier, Jeanneret, 1935
Como consecuencia de la exposición de Paris de 1922 y del diorama de la Ville contemporaine expuesto en el Salon d'Automne, la popularidad de Le Corbusier como "arquitecto moderno" aumenta enormemente obteniendo un contrato para escribir el libro Vers une architecture (1923) y recibiendo el encargo para construir cuatro viviendas entre las cuales se encuentra la Villa La Roche-Jeanneret (1923). En efecto, con este plan, la idea de "urbanismo moderno" aparece representada mediante la imagen de ciudad como una "gran máquina" con veloces autos circulando entre enormes edificios acristalados. De este modo, busca armonizar los problemas de las grandes ciudades existentes sustituyendo "el caos" por el orden de un riguroso sistema geométrico. Lejos de intentar modificar los procesos de industrialización y sus consecuencias, fundamenta sus decisiones en respuesta a las "nuevas necesidades" urbanas derivadas del congestionamiento de los centros urbanos, del incremento de la densidad de habitantes, el aumento de los medios de circulación y el déficit de superficies vegetadas. Así, la técnica se presenta como una herramienta "universal" adecuada para modificar este nuevo ambiente metropolitano sin importar su ubicación geográfica y sus condiciones climáticas particulares: la utopía corbusierana asume que la tecnología tiene el poder de restituir la armonía perdida entre el hombre y la naturaleza. 
LA CIUDAD DE LOS AUTOS-AVIONES

El automóvil ha matado la gran ciudad. El automóvil ha de salvar la gran ciudad.

Le Corbusier, 1929

Uno de los inventos modernos más influyentes en el siglo xx ha sido el automóvil. Como menciona Basalla (1988), la búsqueda de los orígenes del auto con motor a gasolina revela que no fueron necesidades primarias las que inspiraron a los inventores para cumplir su tarea. El automóvil no fue desarrollado como respuesta a alguna huelga internacional de caballos o de líderes nacionales, pensadores influyentes, o escritores que abogaran por el desarrollo de una tecnología que pudiera cubrir necesidades sociales y personales de transporte motorizado. En efecto, durante la primera década de existencia (1895-1905) era un juguete, un objeto de diversión para aquellos que podían comprarlo.

Sin embargo, en un corto plazo, el auto comienza a ser percibido como "necesario" y su producción en serie busca convertirlo en un objeto de consumo de masas. Las primeras compañías creadas para fabricar autos masivamente se ubican en Francia y Estados Unidos. Así, si en 1900 el país europeo fabrica solamente trescientos veinte coches por año, en 1913 este número sube a cuarenta y cinco mil convirtiéndose en el segundo productor mundial de vehículos (Ortiz, 2000). Empresas francesas como Peugeot (1891), o su marca posteriormente asociada, Citroën, han sido señaladas como pioneras en la producción en serie fuera de los Estados Unidos. Hacia 1921 se pueden observar diversas marcas de automóviles y el desarrollo de autos de lujo. Un ejemplo significativo es el caso de la marca francesa de aviones y automóviles Voisin, establecida por Gabriel Voisin, pionero de la aviación, quien en 1919 había comenzado a producir automóviles indagando sobre la utilización de un amplio uso de diversas aleaciones ligeras, especialmente de aluminio, siendo uno de los primeros diseñadores en utilizar esta tecnología avanzada.

En 1925, Le Corbusier es invitado a participar de la Exposición Internacional de las Artes Decorativas en Paris y, bajo el programa de "reforma de la habitación," presenta el pabellón L' Espirit Noveau en donde se exponen desde objetos utilitarios hasta proyectos de urbanización de grandes ciudades sirviendo también como propaganda de la revista titulada con el mismo nombre. El pabellón en sí mismo era del tipo immeuble villa y junto a este se había construido un sector anexo de paredes curvas en donde se podían ver dioramas de los proyectos de una Ville contemporaine pour trois millions d'habitants, de 1922, y la puesta en práctica de estos aportes teóricos en París a través del Plan Voisin pour Paris, proyecto denominado así en referencia a la firma de aviones y autos Voisin que financiaba la construcción del mencionado pabellón.

Como el auto ha revolucionado las bases seculares del urbanismo, concebí el proyecto de interesar a los fabricantes de autos en la construcción del pabellón L'Espirit Noveau en la Exposición Internacional de las Artes Decorativas ... Vi a los directores de las casas Peugeot, Citroën, Voisin 
y les dije: 'El auto ha matado la gran ciudad. El auto debe salvar la gran ciudad. ¿Quieren ustedes dotar a París de un plan Peugeot, Citroën, Voisin de Paris? ¿De un plan que tenga como único objeto fijar la atención del público sobre el verdadero problema arquitectónico de la época, problema que no es del arte decorativo sino de arquitectura y urbanismo: la constitución salubre de la vivienda y la creación de órganos urbanos que respondan a condiciones de vida modificadas tan profundamente por el maquinismo?' La casa Peugeot temió arriesgar su nombre en nuestra empresa de aspecto tan temerario. El señor Citroën, muy gentilmente, me respondió que no comprendía nada de lo que le decía y que no veía la relación que podía tener el automóvil con el centro de París. El señor Mongermon, administrador delegado de Aeroplanes G. Voisin (Automobile) aceptó sin titubear el patronazgo de los estudios del centro de París y el plan que resultó de ellos se denominó, por tanto, Plan Voisin de París. (Le Corbusier, 2001, p. 35)

Para Le Corbusier, el centro urbano de París estaba demasiado congestionado debido a sus dimensiones y había quedado obsoleto para las necesidades impuestas por la época de la velocidad: la irrupción del intenso tráfico rodado que en el incipiente siglo xx se estaba produciendo. La conformación de la metrópoli, tal como estaba, no podía dar respuesta a los requerimientos propios de su tiempo que demandaban infraestructuras de mayor escala. En consecuencia, el proyecto es presentado dentro de una idea de "urbanismo actual y proyecto arquitectónico" basado en datos concretos y en "la fiabilidad probada de ciertos materiales" planteando como objetivo tanto una nueva forma de organización social y económica como una explotación más racional de los bienes inmuebles. Afín con su patrocinador, el plan cuestionaba la idea de "calle" tal y como había sido concebida hasta ese momento priorizando la circulación vehicular y otorgándole protagonismo a los medios de transporte.

La calle ya no es solo la tierra firme sino una máquina para circular, un aparato circulatorio, un órgano nuevo, una construcción en sí y de decisiva importancia, una especie de fábrica longitudinal que necesita uno o dos pisos y que sería posible, recurriendo meramente al buen sentido, ponerse a ejecutar las ciudades-pilotes, solución cándida, ejecutable en cualquier momento. (Le Corbusier, 2001, p. 40)

Para poder llevar a cabo el mencionado plan, era necesario demoler más de doscientas cuarenta hectáreas del centro histórico parisino en la ribera derecha del Sena, zona señalada como "insalubre y anticuada". El sector a intervenir tomaba como límites lugares relacionados con el transporte: estaciones de trenes, calles e hitos urbanos como la plaza o un roind point (elemento organizador del tránsito). Así, el proyecto estaba compuesto básicamente por dos rectángulos que conformaban, por un lado, al oeste, un "centro de residencia" con programas de viviendas, equipamientos culturales y gubernamentales, y por el otro, al este, la "Ciudad de los Negocios" en donde se ubicaría una zona de dieciocho rascacielos de oficinas cuyas pisadas solamente ocuparían el cinco por ciento de la planta baja liberando los terrenos entre edificios y permitiendo la conformación de sectores de áreas verdes y peatonales. Tal 
como había proyectado en la Ville contemporaine..., la estación central sería subterránea, se ubicaría entre ambos centros, residencial y de negocios, y funcionaría como "puerta de acceso" a la nueva ciudad. El eje principal del trazado, posicionado de este a oeste, sería una "arteria principal" de gran circulación, de 120 metros de ancho, provista de una autopista sobreelevada para la circulación en un solo sentido.

En adelante, en lugar de una ciudad chata y apretada, y tal como la revela el avión por primera vez a nuestros ojos, nos quedamos azorados (véase las fotos de la Compañía Aérea Francesa); se yergue una ciudad hacia la altura, abierta al aire y la luz, resplandeciente de claridad, radiante. El suelo, recubierto hasta ahora de casas apiñadas sobre el $10 \%$ al $80 \%$ de su superficie, no está ahora construido más que en el $5 \%$. El resto, el $95 \%$, está consagrado a las grandes arterias, a los garajes de estacionamiento y a los parques. Las avenidas de sobras son dobles a cuádruples; parques al pie de los rascacielos hacen del suelo de esta nueva ciudad, un enorme jardín. (Le Corbusier, 2001, p. 53)

La confianza de Le Corbusier en la técnica era tal que su propuesta no admitía una relocalización de este "Centro de Negocios" sino que inevitablemente recurría a la tabula rasa. Motivado por generar un drástico cambio en París, el proyecto destruía el legado histórico de los barrios medievales y de los edificios de la zona, dejando aislados, como monumentos, solamente algunas obras significativas como el Louvre y el Palais Royal entre otros. El Plan Voisin pour Paris no destruía totalmente el pasado urbano de la ciudad, pero lo reconstruía poniendo como protagonista a la máquina, transformando la noción del tiempo impuesta por la rapidez y velocidad de los nuevos inventos modernos como el auto y manifestando una idea de bienestar construida sobre estos principios (figura 2).

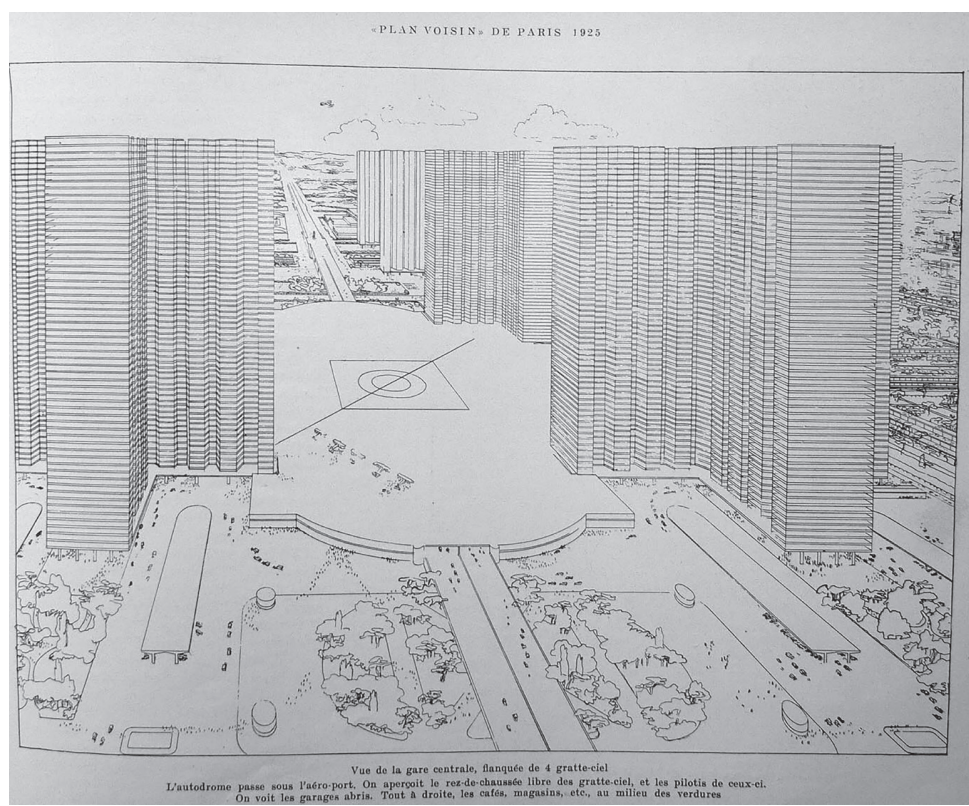

Figura 2.

Perspectiva del Plan Voisin pour Paris. Nótense los aviones en la plataforma elevada

\section{Fuente:}

Le Corbusier, Jeanneret, 1935 
LA CIUDAD DEL "CLIMA HECHO POR EL HOMBRE”

Urbanizar no es gastar dinero / es ganar / es hacer $o$, de otra manera: urbanizar no es despreciar, no es desvalorizar es valorizar ... La situación se transforma; el problema es completamente nuevo; es positivo y no negativo. Es constructivo. Conduce a unas operaciones de valorización de las ciudades. Por consiguiente, el urbanismo valoriza.

Le Corbusier, 1929

La idea moderna de "acondicionamiento de aire" se basa en el proceso de tratamiento de la temperatura, ya sea por calefacción o refrigeración, el grado de humedad, la renovación o circulación y la limpieza o purificación del aire en un ambiente cerrado. El origen de este invento se puede relacionar con el científico británico William Thomson Kelvin quien en 1845 descubre los principios físicos que posibilitan la creación del aire acondicionado; pero, principalmente, con el ingeniero estadounidense Willis Haviland Carrier, denominado el "padre del aire acondicionado," quien en 1902, frente a la necesidad de resolver las fallas en las impresiones de color que la compañía litográfica y de publicaciones neoyorquina Sackett-Wilhelms sufría debido a las variaciones térmicas e higrométricas que se experimentaban en sus talleres de producción, ideó un sistema para controlar el calor y la humedad ambiente. Así, surgió el primer "aparato de tratamiento del aire" o como era llamado por su inventor "clima hecho por el hombre" que fue patentado en 1906 sentando las bases del moderno aire acondicionado y el desarrollo del concepto "climatización" (figura 3).

La frase "clima hecho por el hombre" es admirable, no solo para describir el producto final del proceso del aire acondicionado, sino también para subrayar hasta qué punto el dominio del arte de Carrier dependió de la observación directa de la naturaleza y del comportamiento del aire como componente del clima exterior. Fue así como su patente más crucial -el control de punto de rocío-, cuya solicitud se registra en el annus mirabilis de este negocio - 1906-, dependió de una observación personal sobre los efectos de la niebla en una estación ferroviaria de Pittsburgh, hacia el año 1902. (Banham, 1975, p. 15)

Como estudió Reyner Banham, durante los años posteriores, el objetivo principal de Carrier fue mejorar el desarrollo de procesos industriales a través de continuos cambios tecnológicos que permitieran el control de la temperatura y la humedad, ya que el mejoramiento del confort humano favorecía la eficiencia de la fuerza de trabajo mejorando la rentabilidad de las empresas. Debido a la mejora de sus productos, un gran número de industrias, tanto nacionales como internacionales, comenzaron a instalar equipos de tratamiento de aire. Claros ejemplos fueron las industrias del tabaco, laboratorios farmacéuticos, máquinas de afeitar y panaderías. Comenzada la Primera Guerra Mundial, Carrier, junto con seis colegas, invirtieron en su propia compañía: Carrier 
Engineering Corporation desarrollando para 1922, la "enfriadora centrífuga", un nuevo sistema de aire acondicionado que permitía refrigerar desde los sótanos de grandes almacenes hasta las tiendas. Dicho invento fue, debido a su éxito, instalado en poco tiempo en hospitales, rascacielos de oficinas, aeropuertos, fábricas y hoteles. En 1925 la compañía recibe el encargo de climatizar el cine Rivoli de Nueva York realizándose una gran campaña de publicidad que llega rápidamente a los ciudadanos con tal éxito que, para 1930, alrededor de trescientos cines estadounidenses tenían instalado este sistema de refrigeración. Durante 1928, la empresa sacó al mercado un equipo residencial que enfriaba, calentaba, limpiaba y hacía circular el aire y cuya principal aplicación era la doméstica. De esta manera, quedaba instalada la necesidad de la climatización artificial.

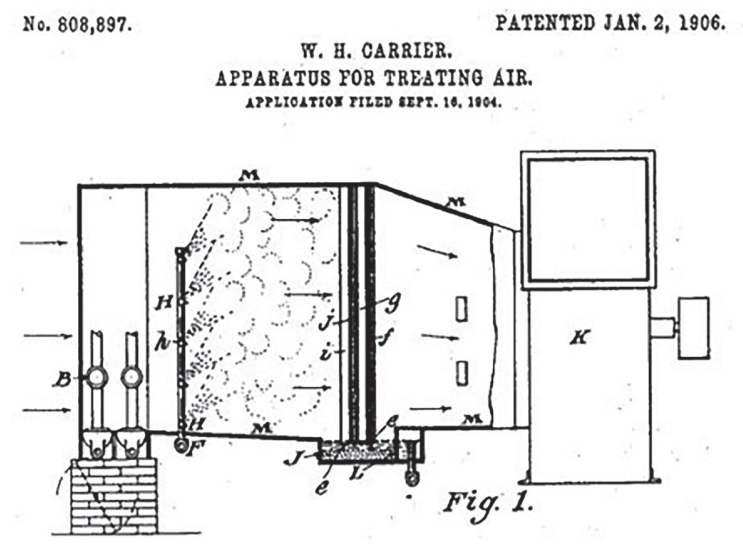

Figura 3.

Equipo Carrier

Fuente: figura presentada para la patente, 1906

Por su parte, bajo la premisa de densificar centros urbanos y construir "ciudades en altura", el desarrollo de pensamiento de Le Corbusier desde la Ville contemporaine, mediante la construcción de la tipología de rascacielos cruciformes materializados con cerramientos herméticos de vidrio, hasta el "Centro de Negocios" del Plan Voisin pour Paris, con una propuesta de construir dieciocho de estos rascacielos cruciformes aptos para contener entre veinte mil y cuarenta mil empleados, sugiere la necesidad de utilizar técnicas de climatización artificial.

Partiendo del acontecimiento constructivo capital que es el rascacielos norteamericano, bastaría reunir en algunos puntos determinados esta gran densidad de población y elevar allí, en 60 pisos, construcciones inmensas. El cemento armado y el acero permiten estas audacias y se prestan sobre todo a un cierto desarrollo de las fachadas, gracias al cual todas las ventanas darán a pleno cielo; así, además, los patios quedarán suprimidos. A partir del piso catorce, reina la calma absoluta, el aire puro. (Le Corbusier, 1964, p. 21)

Mientras que las tipologías de viviendas zigzagueantes (en redient) buscaban cuestionar el modelo prismático planteado por Haussmann en el París del siglo 
Figura 4

Maqueta de los rascacielos cruciformes del sector

"Ciudad de los

Negocios", Plan

Voisin... (1925)

Fuente:

Le Corbusier,

Jeanneret, 1935
XIX, la torre cruciforme con grandes cerramientos de vidrio era una respuesta a los rascacielos neogóticos y eclécticos de moda en Estados Unidos. Las torres vidriadas buscaban funcionar como emblemas del nuevo orden económico y como símbolo del "espíritu de su tiempo" (Curtis, 1997). Le Corbusier llegará incluso a argumentar que cada época ha desarrollado sus propios tipos y los rascacielos son los representativos del siglo xx por responder a las necesidades de su tiempo vinculadas tanto con la congestión del tránsito como con la renta de suelo: el urbanismo moderno y los rascacielos "valorizaban". Así, la idea de modernidad es presentada como la propagación de una "caja climatizada" igual en todas partes y esta "arquitectura climatizada" pasará a ser un fundamento en la concepción del arquitecto, quien, entusiasmado, describirá que tras las imponentes fachadas de vidrio es posible generar un clima artificial similar al marítimo de Costa Azul (Le Corbusier, 1933-1934) (figura 4). En efecto, durante su visita a Buenos Aires en 1929, donde hará mención del plan Voisin..., argumentará: "Cada país construye sus casas en función de su clima. En esta época de interacción general de técnicas científicas internacionales, propongo una sola casa para todos los países y para todos los climas: la casa con respiración exacta" (Le Corbusier, 1999).

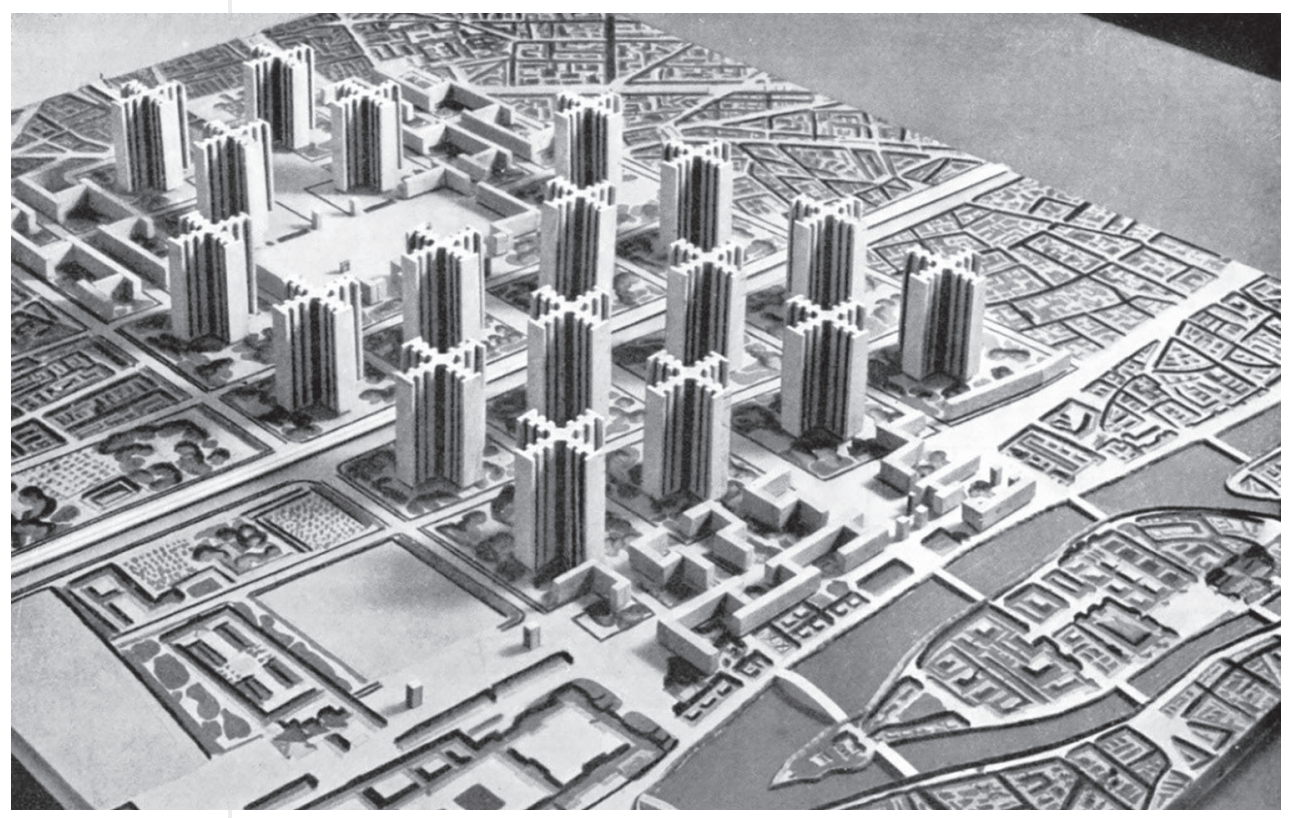

Sin embargo, como menciona Banham, esta voluntad de mejoramiento de la tipología estadounidense responderá principalmente a cuestiones teóricas y no tanto tecnológicas ya que si se consideran los aportes del arquitecto al tema del tratamiento del aire "habría sido necesario inventar el aire acondicionado hacia el año 1930” (Banham, 1975, p. 38). La idea de cerramiento continuo de vidrio 
insinuada en el rascacielos cruciforme buscaba garantizar el bienestar de sus usuarios sustituyendo la utilización de muros y ventilación natural mediante el uso de grandes placas de vidrio (denominadas por el arquitecto como mur neutralisant y pan de verre) y el auxilio de los medios mecánicos (la respiration exacte) justificando su existencia en la necesidad de evitar el contacto con el aire metropolitano viciado por la polución y el smog. Le Corbusier comenzará a desarrollar esta idea, según su propio relato, desde 1916, por un lado, a partir de los experimentos del "primer investigador del tema en Europa" el director de la compañía de vidrios Saint Gobain, Gustave Lyon, cuyos "estudios, empezados largo tiempo atrás, fueron independientes de las tentativas que también se hacían en los Estados Unidos para proveer aire puro" (Le Corbusier, 1948). Por el otro, durante 1927, con el proyecto del Palacio de las Naciones mediante el desarrollo de "paredes neutralizantes" (mur neutralisant) y en 1929, a través de la idea de pan de verre (panel de vidrio o lo que se traducirá como "muro cortina") un sistema conformado por dos vidrios entre los cuales se haría circular aire en la cámara hasta lograr en ella una temperatura constante, "aire exacto," para equilibrar las condiciones exteriores. Un esquema que, básicamente, en Estados Unidos ya tenía una forma comercial desarrollada por Carrier y que, en 1930, la empresa American Blower Corporation, a petición del arquitecto tras distintas experiencias realizadas en Saint Gobain, enviará un informe en el que concluye: "El método que usted propone requiere cuatro veces más de vapor y duplica la energía consumida en comparación con los sistemas de climatización ya comercializados" (Ábalos y Herreros, 1992, p. 123).

Más aún, en 1929, Le Corbusier logrará materializar estas ideas de manejo del entorno ambiental, "respiración exacta" y mur neutralisant, en la sede del Ejército de Salvación, la Cité de Refuge, inaugurada triunfalmente durante el crudo invierno de diciembre de 1933.

Allí viven seiscientos pobres diablos, hombres y mujeres. Se les dio la alegría gratuita e inefable de la plena luz y del sol. Una vidriera de mil metros cuadrados ilumina las habitaciones de piso a techo, de pared a pared. El gobernador de la Cité nos decía, la semana pasada, que la alegría dispensada de ese modo hacía marchar maravillosamente su organización, con pleno rendimiento. La vidriera era hermética, ya que el aire calentado y purificado circulaba abundantemente en el interior, regulado por las bombas y la calefacción. (Le Corbusier, 1948, p. 41)

Una alegría que a los "pobres diablos" le duró poco ya que, al llegar el verano, los grandes ventanales herméticos convirtieron al interior en un invernáculo insoportable que será descripto por crónicas de la época: "En el interior ... ventilación mecánica. De noche, cuando los motores dejan de trabajar, reina un hedor insoportable. Pero el muro, todo de vidrio, está cerrado herméticamente" (Vago, 1933-1934, p. 323).

Así, como señala Banham, los problemas de la Cité se debieron, por un lado, a cuestiones de déficit presupuestario que llevaron a realizar los muros de vidrios con una sola placa (y no como había sido pensado originariamente el mur neutralisant) pero incluso aunque se hubiera materializado con las dos 
láminas tampoco hubiera funcionado, ya que las mismas restricciones económicas también impidieron la adquisición de un equipo de enfriamiento del sistema de ventilación y obligaban a apagar las máquinas durante la noche. Finalmente, la historia de este edificio concluye con una remodelación que incorpora ventanas de abrir y contribuye a que Le Corbusier invente el parasol exterior o brise-soleil.

Cabe preguntarse qué hubiera ocurrido con el "clima hecho por el hombre" en los rascacielos cruciformes de sesenta pisos.

Cada época sueña la siguiente.

Walter Benjamin

A lo largo del texto se pudo observar la utilización de innovaciones tecnológicas en proyectos urbanos de principio de siglo xx y su incidencia en la forma de diseñar las ciudades. Con el proyecto de la Ville contemporaine..., la idea de una "ciudad máquina" quedó evidenciada en la posibilidad de implantarse en cualquier región o geografía, en su forma rigurosamente geométrica resultado de la plena confianza en la racionalidad científica y en la importancia atribuida a los medios de transporte motorizados pensables como el mecanismo de movimiento de una maquinaria. Con el Plan Voisin pour Paris se pudo, por un lado, comprobar la importancia que adquiere el automóvil en la conformación de la idea de bienestar moderno a principios del siglo $\mathrm{xx}$ y el protagonismo que pasa a ocupar en la ciudad justificando la demolición del patrimonio histórico de la ciudad medieval. Por el otro, con la invención de los rascacielos cruciformes implantados en extensos paisajes vegetados propuestos para una "Ciudad de los Negocios" se pudo observar un discurso materializado a través de propuestas artificiales como el "clima hecho por el hombre" pero paradójicamente basado en la necesidad de retornar a la naturaleza.

Es fácil señalar, con la distancia de casi un siglo, el proyecto utópico presente en las ideas urbanísticas modernas de principios del siglo xx. El discurso corbusierano cuestiona la ciudad de su tiempo, pero no cuestiona la idea de necesidad de la ciudad metropolitana como una concentración jerarquizada de millones de habitantes que circulan en vehículos motorizados a grandes velocidades y habitan en ambientes preparados artificialmente tomando prestadas tecnologías diseñadas para fábricas e industrias.

En este sentido, como señalaba Ortega y Gasset, detrás de toda invención se encuentran las motivaciones de un determinado tiempo y cultura siendo entonces el estudio de las técnicas una forma de comprender cuáles fueron aquellas percepciones de bienestar que motivaron la creación de ciertos inventos y modificaron las formas de vivir en la ciudad. Desde este enfoque, el estudio de las imágenes generadas por Le Corbusier para expresar sus teorías 
sugiere un modelo de arquitectura y urbanismo "internacional" pensado en función de la necesidad de reconstruir las ciudades y su sociedad sobre el ideal decimonónico de progreso sociocultural ilimitado del avance tecnológico.

Desde el año 2010, la empresa alemana de autos de lujos Audi promueve el desarrollo de un concurso de ideas denominado Audi Urban Future que tiene como objetivo estimular "nuevas visiones" para las ciudades y la movilidad urbana. El equipo ganador del primer premio fue el estudio dinamarqués BIG con un plan denominado Driverless City. Sustentado en los últimos desarrollos tecnológicos computarizados driverless car de la marca alemana que han posibilitado la creación de autos sin conductor, el proyecto propone una infraestructura para el tránsito digitalizada y si bien el concurso está inscripto dentro de una competencia de ideas, los dibujos sugieren la necesidad de "demoler" las calles existentes para construir estas innovadoras vías de circulación.

La necesidad de los "autos sin conductor" ha sido inventada.

\section{REFERENCIAS}

Ábalos, I. y Herrero, J. (1992). Técnica y arquitectura en la ciudad contemporánea. Madrid: Editorial Nerea.

Banham, R. (1975). La arquitectura del entorno bien climatizado. Buenos Aires: Ediciones Infinito

Basalla, G. (1988). The evolution of Technology. Reino Unido: Cambridge History of Science Series

Curtis, W. (1997). Le Corbusier: Ideas and Forms. Londres: Phaidon Press Limited.

Framtpon, K. ( 2002). Le Corbusier. Madrid: Ediciones AKAL.

Le Corbusier. (1933/1934). Discours d'Athènes, iv. Congrès d'Architecture Moderne, aout 1933. L'Architecture d'Aujourd'hui 10(81).

Le Corbusier. (1948). Cuando las catedrales eran blancas. Viaje al país de los tímidos. Buenos Aires: Editorial Poseidón.

Le Corbusier. (1964). Hacia una arquitectura. Buenos Aires: Editorial Poseidón.

Le Corbusier. (1999). Precisiones. Respecto a un estado actual de la arquitectura y el urbanismo. Barcelona: Ediciones Apóstrofe.

Le Corbusier. (2001). La ciudad del futuro. Buenos Aires: Ediciones Infinito.

Le Corbusier, Jeanneret, P. (1935). Oeuvre Complete de 1910-1929. Zurich: Editions H. Girsberger.

Ortiz, R. (2000). Modernidad y espacio. Benjamin en París. Bogotá: Grupo Editorial Norma. 
Passanti, F. (1987). The Skycrapers in the Ville Contemporaine. Assamblage, 4, 53-65.

Vago, P. (1933-1934). Le Corbusier et l'architecture d'aujourd'hui. L'Architecture d'Aujourd'hui, 10, 3-5.

Von Moos, S. (2002). Le Corbusier Before le Corbusier: Architectural Studies, Interiors, Painting and Photography, 1907-1922. Connecticut: Yale University Press.

Von Moos, S. (2009). Le Corbusier: Elements of a Synthesis. Rotterdam: 010 Publishers. 